\title{
Foam Generation, Propagation and Stability in Porous Medium
}

\author{
Arne Skauge $\mathrm{A}^{1,2}$ (D) Jonas Solbakken ${ }^{3} \cdot$ Per Arne Ormehaug ${ }^{3}$. \\ Morten Gunnar Aarra ${ }^{3}$
}

Received: 16 April 2018 / Accepted: 20 February 2019 / Published online: 11 March 2019

(c) The Author(s) 2019

\begin{abstract}
There have been several foam field applications in recent years. Foam treatments targeting gas mobility control in injectors as well as gas blocking in production wells have been performed without causing operational problems. The most widely used injection strategy of foam has been injecting alternating slugs of surfactant in brine with gas injection. This procedure seems to be beneficial as injection is easy to perform and control below fracturing pressure. Simultaneous injection of surfactant solution and gas may give difficulties, especially with interpretation of the tests, if fracturing pressure are exceeded during the injection period. This paper reviews critical aspects of foam for reservoir applications and intends to motivate for further field trials. Key parameters for qualification of foam are: foam generation, propagation in porous medium, foam strength and stability of foam. Stability is discussed, especially in the presence of oil at reservoir conditions. Data on each of these topics are included, as well as extracted summary of relevant literature. Experimental studies have shown that foam is generated at low surfactant concentration even below the CMC (critical micelle concentration). Results indicate that in situ foam generation in porous medium may depend on available nucleation sites. In situ generation of foam is complex and has been found to be especially difficult in oil wet carbonate rocks. Foam propagation in porous medium has been summarized, and propagation rate for a given experiment seems to be constant with time and distance. Laboratory studies confirm a propagation rate of $1-3 \mathrm{~m} /$ day. Field tests performed have not given reliable information of foam propagation rate, and future field pilots are encouraged to include observation wells in order to gain information of field-scale foam propagation. Foam strength is generally high with all gases. The exception is $\mathrm{CO}_{2}$ at high pressure where $\mathrm{CO}_{2}$ becomes supercritical. Stability of foam has been studied in laboratory and field tests, and has confirmed long-term stability of foam.
\end{abstract}

Keywords Foam · Foam generation · Foam propagation $\cdot$ Stability of foam

\footnotetext{
Arne Skauge

arne.skauge@uib.no

1 Department of Chemistry, University of Bergen, 5020 Bergen, Norway

2 Energy Research Norway, Bergen, Norway

3 NORCE Energy, CIPR, Bergen, Norway
} 


\section{Introduction}

Oil recovery by gas injections is the most widely used recovery method for light, condensate and volatile oil reservoir. Typical gases that are used include $\mathrm{CO}_{2}$, hydrocarbon gases (e.g., $\mathrm{CH}_{4}$ ), $\mathrm{N}_{2}$, air and steam. The "choice" of gas composition in a field situation depends on several factors such as gas availability, recovery conditions (miscible/immiscible) and many technical and economical evaluations of which fluids are appropriate for the field.

Gas injections for improving oil recovery often lead to early gas breakthrough, and poor volumetric sweep efficiency of the reservoir, and later stage severe problem with gas handling and/or recycling of gas. Displacement instabilities and poor sweep during gas injections can be traced to the low viscosity and density of injected gas, but also coupled to reservoir heterogeneity.

Foam has been applied for gas shutoff in production wells, and as a mobility control agent especially in gas injection of WAG (water alternating gas) operations where early gas breakthrough may occur. Recent field experiences (Blaker et al. 2002; Skoreyko et al. 2011; Ocampo-Florez et al. 2014; Ocampo et al. 2018) have proved that foam improves sweep efficiency and can divert injected gas. In addition, foam may increase the oil plateau period for mature oil fields by reducing the gas/oil ratio for wells suffering from high gas production. The foam processes, both production- and injection well treatments, are considered rather low-cost processes.

Foam is defined as a dispersion of gas in liquid (Hirasaki 1989; Kovscek and Radke 1994) and has been utilized as a tool for gas mobility- and conformance control in porous media for a wide range of applications, since the late 1950s. Industrial applications of foam in porous formations include enhanced oil recovery (EOR) (Aarra and Skauge 2000; Enick and Olsen 2012; Rossen 1996; Zhdanov et al. 1996), matrix-acidizing treatments (Thompson and Gdanski 1993; Parlar et al. 1995; Zeilinger et al. 1995), improved underground storage of gas (Smith and Jikich 1993), as well as contaminated-aquifer remediation (Hirasaki et al. 1997). Despite its unique properties, broad applicability and extensive experience gained over the past 60 years, foam has not become a standard reservoir engineering oil recovery process. One reason may be the lack of predictive foam flow models in porous medium.

A successful well treatment with foam is critically depended on the correct placement of foam with specific properties to stimulate the current reservoir problems. Specific foam properties can include strong and stagnant foams (i.e., very low mobility foams) for production well treatments to reduce unwanted high gas/oil ratio (GOR). While relatively, weaker and more mobile foams can be more optimal to support the gas injection front with mobility control deeper into the porous formation without impairing injectivity. Accordingly, a sound understanding of the problem to be solved, reservoir properties and foam properties in porous media becomes important.

This paper focuses on foam generation, propagation and stability in porous media in relation to EOR processes. The efficiency of foam to reduce gas mobility (i.e., foam generation), the injection time required for foam to reach a given depth in the reservoir (i.e., foam propagation) and foam lifetime and persistence to various conditions during as well as after its placement (i.e., foam stability) are key questions for all intended field applications with foam in relation to EOR.

Gas injections for EOR often lead to early gas breakthrough, meaning poor volumetric sweep efficiency of the reservoir and later severe handling and/or recycling of gas. Application of foam can be a technically feasible way to overcome the shortcomings of gas injections. In fact, if correctly designed, foam can be formed within the reservoir when gas and surfactant 


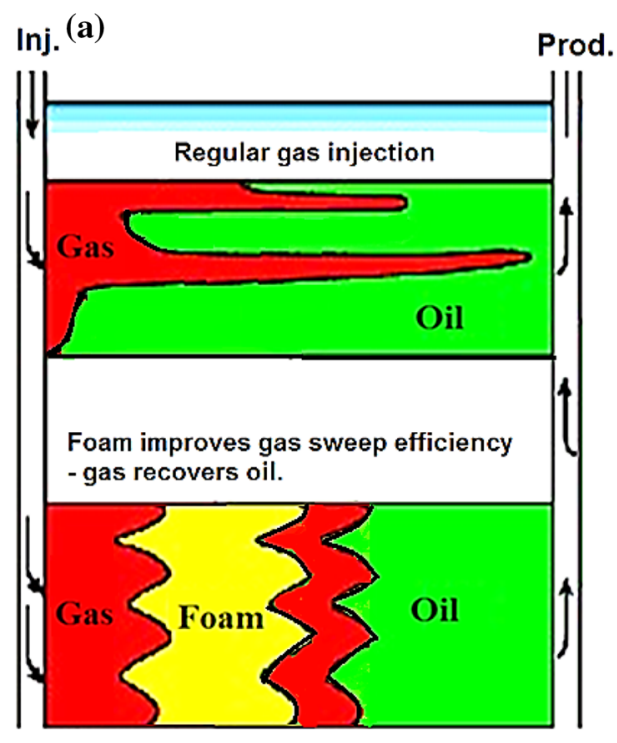

(b)

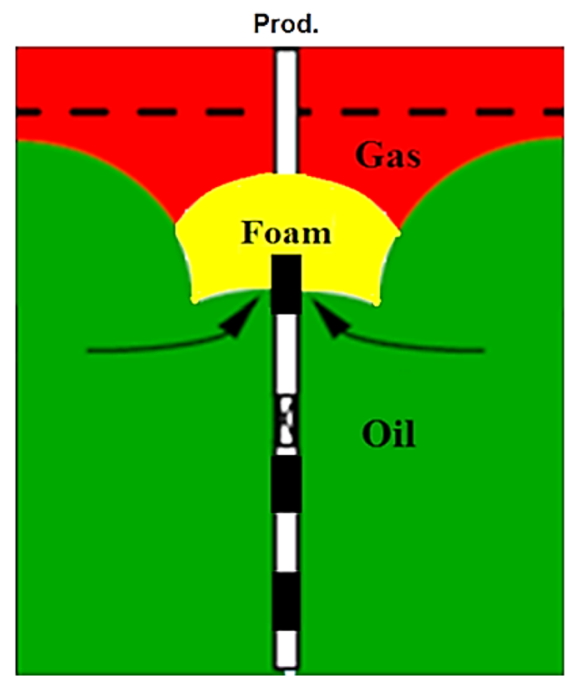

Fig. 1 Field applications of foam for EOR: a injection well treatments; support gas injections with improved mobility control, b production well treatments; prevent unwanted fluids from coning, cusping or channeling into the wells (i.e., GOR/WOR control)

solution flow together, which can potentially overcome all the three sources of poor sweep efficiency recently addressed by gas injections.

Foam can reduce gas mobility and divert gas to unswept areas of the reservoir, thus, supporting gas injections to improve its sweep efficiency and to recover more oil. In addition, foam has demonstrated effective as a tool to block unwanted gas production in production wells (Fig. 1). The foam processes, both production- and injection well treatments, are considered rather low-cost processes.

An illustration of foam applications for EOR is given in Fig. 1. The reservoir problems to be handled by foam treatment should be relevant to oil fields/reservoirs suffering from early gas breakthroughs, poor sweep efficiency of injected fluids, unwanted high gas production and/or undesirable high levels of gas recycling.

Foams can be generated at very low surfactant concentrations, including below the critical micelle concentration (CMC), Fig. 2. The foam generation at low surfactant concentration has been extensively documented (Sanchez and Schechter 1989; Alkan et al. 1991; Kuhlman et al. 1992; Dixit et al. 1994; Heller 1994; Tsau and Grigg 1997; Apaydin and Kovscek 2001; Mannhardt and Svorstøl 2001; Vikingstad et al. 2006; Fekarcha and Tazerouti 2012; Simjoo et al. 2013; Rohani et al. 2014). Especially properties of alpha olefin sulfonates (AOS) have been studied, as in Fig. 2, where we compare data for, foam height, aqueous solution viscosity and speed of sound, as a function of surfactant concentration. The CMC is detected by an abrupt change in aqueous solution speed of sound at surfactant concentration of $0.0022 \mathrm{wt} \%$. Higher surfactant concentration shows increasing foam height even if the solution properties of surfactant changes from spherical micelles to larger structures like ellipsoids or laminal structures.

In order to understand the influence of oil saturation on foam, more fundamental experimental studies have been performed. The static foam properties have been investigated by 


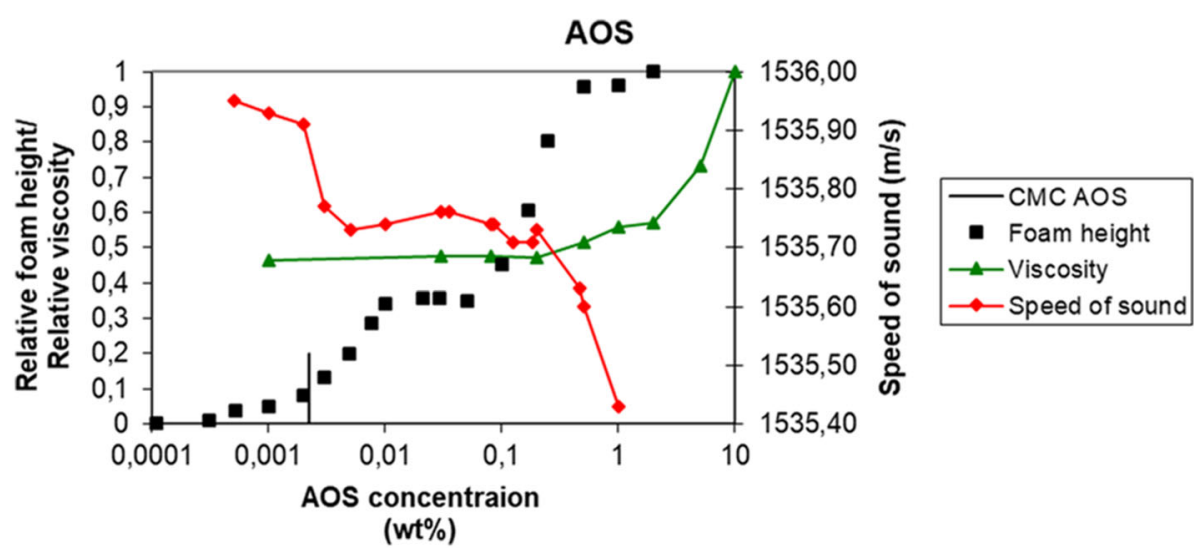

Fig. 2 Static foam height versus surfactant concentration compared to changes in aqueous solution properties (viscosity at a shear rate of $10 \mathrm{~s}^{-1}$ and speed of sound at ambient conditions)

variation in surfactant concentration, amount of added oil and variation in polarity of the oil phase.

The foam generation and foam stability in static foam tests is found to be related to the structure of the surfactant aggregate in the water phase. The foam quality in the presence of alkane-type oils is related to the ability of the surfactant to solubilize the oil molecules (Vikingstad et al. 2006). The viscosity ratio between oil and water is also important for foam stability.

For crude oil, systematic multi-variant analysis has been used to identify the most important factors influencing foam stability (Vikingstad et al. 2005). The variables investigated were acid number, base number, oil viscosity, content of saturates and asphaltenes, interfacial tensions and spreading coefficients.

\section{Materials and Methods}

Foam tests involved static mixing of air into a surfactant solution. The procedure has been described elsewhere Vikingstad et al. 2005). Air was dispersed into the 300-ml test solution at a speed of $2000 \mathrm{rpm}$ (rounds per minute) for $5 \mathrm{~min}$ using a static mixer. Solutions were mixed in 1000-ml glass cylinders measuring $44 \mathrm{~cm}$ high and $6 \mathrm{~cm}$ in diameter. During mixing, there were unlimited air supply and no restrictions on foam expansion. After mixing, the glass cylinder was closed with a plastic seal. Foam height was always well below the top. The experiments were performed at ambient conditions. All of these experiments were performed in synthetic seawater.

In addition to the static foam tests, viscosity and speed of sound measurements were performed for AOS bulk solutions. A large surfactant concentration interval was investigated. The viscosity of the solutions was measured using a Physica MCR 300 Rheometer. All the experiments were performed at room temperature. The shear rate was $101 / \mathrm{s}$ in the measurements. The speed of sound of the bulk surfactant solutions was measured at $(25.000 \pm 0.003){ }^{\circ} \mathrm{C}$ by the Rubidium clock sound velocimeter described elsewhere (Høgseth et al. 2000). The speed of sound cells was calibrated with water using the data of Del Grosso and Mader (1972). The estimated error in the measurements was $0.02 \mathrm{~m} / \mathrm{s}$. 


\section{Foam Generation}

Foam generation and foam coalescence in porous media have been divided into three generation processes: snap-off, leave behind and lamella division and two destabilizing processes: capillary-suction coalescence and diffusion coalescence (Kovscek and Radke 1994; Rossen 1996). Recently, two new generation mechanisms involving interactions between neighboring bubbles have been discovered: "neighbor-neighbor pinch-off" and "neighbor-wall pinch-off" (Liontas et al. 2013).

Foamability and foam stability are important topics in evaluating surfactants for possible use in field applications of foam. The ability of surfactants to generate foam at low concentrations can be very important if performing a water alternating gas process after a foam operation where the ability to generate high mobility foams can improve sweep efficiency and possibly increase the extension of the three-phase region.

\subsection{Minimum Surfactant Concentration}

Investigation of foamability and stability at a range of different surfactant concentration for the two surfactants, FS-500, a perfluoroalkyl sulfobetaine and an alpha olefin sulfonate (AOS) surfactant has been examined in our previous publications (Vikingstad et al. 2005, 2006). The critical micelle concentration (CMC) was measured to $0.0028 \mathrm{wt} \%$ for the FS-500 surfactant, whereas CMC for the AOS surfactant was measured to $0.0022 \mathrm{wt} \%$. The foam generation ability was connected with surfactant concentration and was most profound for the AOS surfactant, but the experiments showed that both surfactants generated foam even below CMC.

There is a lack of correlation between static foam and foam generated in porous medium. Adsorption of surfactant will delay the in situ porous medium formation of foam, but after adsorption equilibrium is achieved, low concentration of surfactant can generate strong foam.

Performing core flooding experiments with the AOS surfactant at reservoir conditions, respectively, $114{ }^{\circ} \mathrm{C}$ and $350 \mathrm{barg}$, using reservoir core material and in the presence of a residual oil saturation showed that strong foams were generated both at $0.1 \mathrm{wt} \%$ and $0.5 \mathrm{wt} \%$ AOS concentrations (Aarra and Skauge 2002).

\subsection{Foam Quality in Porous Medium}

Foam quality is defined as the fraction of gas volume divided by the fraction of gas and surfactant solution volume injected. Several reported core flooding studies report generation of constant water saturations along the cores.

In core flooding studies by Ettinger and Radke (1992), foam texture is considered governed by the porous media itself through strong making and breaking processes. Core flooding studies revealed a constant water saturation of approximately $0.3-0.35$ fraction of pore volume for both in situ and pre-generated foam when the fraction of gas varied between 0.7 and 0.9 at constant water rate. Persoff et al. (1991) report similar water saturation from experiments in $1 \mathrm{D}$ Boise sandstone. Also in our experiments in a North Sea reservoir core at $30 \mathrm{barg}$ and room temperature, a constant water saturation of approximately 0.35 was measured at foam qualities of 50, 65 and 90\% (Fig. 3). Experiments by De Vries and Wit (1990) and Osterloh and Jante(1992) agree with measurements of constant liquid saturation, respectively, 18 and $6 \%$, but find that the pressure gradient not proportional to the increase in liquid velocity at steady state and suggested power law dependence. High foam qualities were used in 


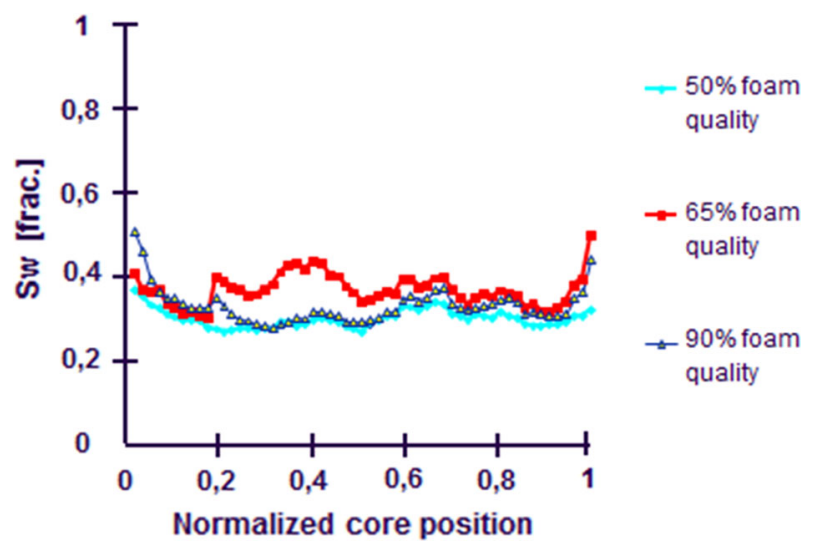

Fig. 3 Water saturation along the reservoir core $\left(0=\right.$ inlet, AOS, 30 bar, room temperature, $\left.S_{\mathrm{O}}=0\right)$

both these studies. Flow at the limiting capillary pressure (Zhou and Rossen 1992) has been introduced.

In EOR applications, foam has been used primarily for conformance and/or mobility control during gas injections or to shut off unwanted gas inflow in production well treatments. Foam properties for conformance control and sweep improvements need the ability to flow large distances, whereas foams for gas shut off applications need to be strong and have high stability.

How to generate, propagate and place foam in optimum position in reservoirs is very important parts of any field application of foam together with a good description of the reservoir problem to treat. The foam could either be generated prior to injection, or in situ in the reservoir. Combination of these to techniques is another alternative. Usually four different foam generation methods might be applied. The first one includes injection of pre-generated foam in which knowledge of foam quality will be very good. A second method involves co-injection of surfactant solution and gas at certain fractional flows. A third option involves the surfactant alternating gas method (SAG) in which slugs of surfactant solution and gas are injected into the reservoirs. The length and volumes under such operations can be design related to the foam quality. The fourth method involves injection of a large slug of surfactant followed by gas. For foams for conformance control and sweep efficiency the injected gas will generate foam in high permeable areas already flooded and swept to a lower oil saturation, and by reducing the gas mobility the injected gas is diverted to new areas and increase the oil recovery. Foams for gas shut off purposes need to be strong and stable to reduce gas from coning, cusping or channeling into the production well.

\subsection{Foam Generation Methods for Field Application}

Examination of several foam field pilots shows that all foam generation techniques have been applied in different pilots. The most used technique is the SAG (surfactant alternating gas) method either alone or combined with co-injection of surfactant solution and gas or with injection of pre-generated foam. Evaluation of the interpretations and results from these foam trials have shown that both positive and negative results have been achieved (Heuer and Jacobs 1968; Krause et al. 1992; Aarra et al. 1996; Aarra and Skauge 2000, 2002; Zhdanov et al. 1996; Thach et al. 1996; Svorstøl et al. 1997; Chukwueke et al. 1998; Blaker et al. 2002; 


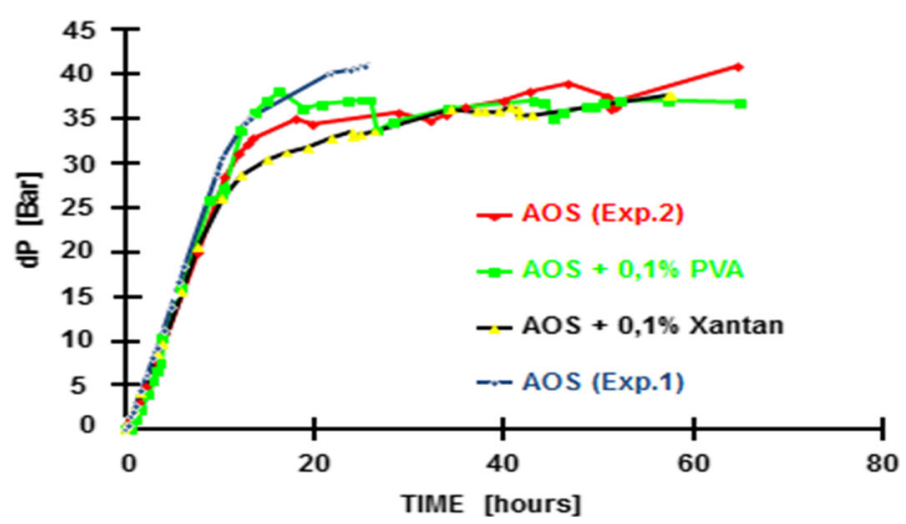

Fig. 4 Foam generation with and without added polymer in Berea sandstone core material at $40{ }^{\circ} \mathrm{C}$ and 110 bar, $S_{\mathrm{O}}=0$

Skauge et al. 2002; Enick and Olsen 2012; Ocampo et al. 2013; Rossen et al. 2017). The surfactant concentration issue discussed earlier, open for testing is foam can be re-freshened with further WAG cycles after SAG. This will counteract the foam drying effect and gravity segregation that may act over time in the reservoir.

\subsection{Foam Quality in Porous Medium}

In some of the field tests, a polymer was added to the water phase together with surfactant. Our experience with polymer-based foams showed that addition of $1000 \mathrm{ppm}$ polymer (PVA or Xanthan) to the AOS surfactant solution in Berea sandstone core material did not seem to change foam formation (Aarra et al. 1997). The results are shown in Fig. 4 and shows that foams of similar strength were generated both with and without polymer added.

\subsection{Minimum Pressure Gradient for Generating Foam}

In the literature, there has been discussed if there is a minimum pressure gradient, which is needed to generate foam. Late studies of Yu et al. (2018) find that there is a critical velocity for foam generation from experiments in Bentheimer sandstone, while Almajid and Kovscek (2016) present foam experiments in silicon micromodels where foam was generated by coinjecting $\mathrm{N}_{2}$ gas and AOS surfactant and observed no critical velocity for foam generation. Foam generation by hindered snap-off and foam coalescence by pinch-off was observed.

\subsection{Minimum Permeability for Generating Foam}

A challenge for foam field application will be application of foam in low permeable heterogeneous reservoirs. Foam generation in low permeable laminated core material has shown generation of foam in low permeable Berea sandstone cores (Solbakken et al. 2014) similar to findings from Siddiqui et al. (SPE 37416 1997). Permeability contrasts within low permeable reservoir can be as severe as in high permeable reservoirs, and specific reservoir characteristics need to be evaluated to find foam properties to improve sweep efficiency and to increase oil recovery. AOS foams have been generated at high residual oil saturations (35-41\%) with 
MRF's ranging from 12 to 67 using three different North Sea oils (Vikingstad and Aarra 2009).

\subsection{Need for Nucleation Sites}

Wettability may influence the in situ foam generation. In sandstones, the heterogeneous mineralogy gives sites with different surface charge and strength of electrostatic properties. In such material, we have never seen any problem of generating foam in situ. Carbonates have in general more homogeneous surface charge and may be more oil wet. The rock surface can be covered with continuous oil films, which is confirmed with no spontaneous water imbibition, while oil is spontaneously imbibed. Foam in some carbonate rock has shown difficulty for in situ foam generation (Aarra et al. 2011). In this study, in situ foam could not be generated, but pre-generated foam was transported through the porous medium.

\section{Foam Propagation}

The efficiency of foam to reduce gas mobility (i.e., foam strength) and its stability are key questions for all intended field applications. Various parameters have been used to determine the efficiency of foam in porous media (Heller 1994), and one common parameter is the mobility reduction factor (MRF):

$$
\text { Mobility Reduction Factor }(\mathrm{MRF})=\frac{\Delta P_{\text {foam }}}{\Delta P_{\text {no-foam }}}
$$

where $\Delta P_{\text {foam }}$ and $\Delta P_{\text {no-foam }}$ are the measured differential pressure across the porous medium with and without foam, respectively, at the same gas/water ratio. A high MRF corresponds to strong foam.

The foam performance offered by a given surfactant may depend on several factors, such as surfactant type and concentration, type of gas and gas composition, rock properties, oil saturation, foam-oil interactions, brine salinity, temperature and pressure conditions, flow rates, injection strategies and so on.

The typically used gases types in foams include $\mathrm{CO}_{2}, \mathrm{~N}_{2}$, air, hydrocarbon gases (e.g., $\mathrm{CH}_{4}$ ) and steam. The "choice" of gas composition in a field situation typically depends on gas availability, the recovery conditions and an economic assessment of the appropriate fluid for the field (Aarra and Skauge 2002; Enick and Olsen 2012; Holm and Garrison 1988; Manrique et al. 2010; Turta and Singhal 1998; Zhdanov et al. 1996).

Several laboratory studies have compared the $\mathrm{CO}_{2}$-foams with the $\mathrm{N}_{2}$-foams in outcrop sandstone core material, without oil, using commercial anionic surfactants, under different experimental conditions. Typically the generated $\mathrm{CO}_{2}$-foams have been significantly weaker (i.e., lower pressure gradients along the porous media) than the $\mathrm{N}_{2}$-foams generated under similar experimental conditions (Chou 1991; Seright 1996; Kibodeaux 1997; Gauglitz et al. 2002; Du et al. 2008; Farajzadeh et al. 2009; Aarra et al. 2014; Zeng et al. 2016). Certain $\mathrm{N}_{2}$-foams in the literature have been extraordinarily strong, reflected by very large pressure gradients along the porous media, which are often $\gg 50 \mathrm{bar} / \mathrm{m}$ (Chou 1991; de Vries and Wit 1990; Friedmann et al. 1991; Kovscek and Radke 1994; Vikingstad and Aarra 2009; Solbakken et al. 2014; Siddiqui et al. 1997; Zeilinger et al. 1995). Laboratory experiments using methane gas have also reported the formation of strong $\mathrm{CH}_{4}$-foams. The generated methane foams have repeatedly demonstrated their robustness under high-pressure and high- 
temperature field conditions (Aarra et al. 1997, 2011; Aarra and Skauge 2002; Holt et al. 1996; Mannhardt et al. 2000; Mannhardt and Svorstøl 2001; Svorstøl et al. 1997).

\section{1 $\mathrm{CO}_{2}$-Foams}

A summary of many studies on $\mathrm{CO}_{2}$-foam in sandstone and in carbonate rock material in the absence of oil reveals that few surfactants can generate a $\mathrm{CO}_{2}$-foam of similar strength and stability under elevated experimental conditions as those reported with the $\mathrm{N}_{2}$ - and $\mathrm{CH}_{4}$ foams. However, all of the studies on $\mathrm{CO}_{2}$-foam referenced below show that the $\mathrm{CO}_{2}$ mobility can be lowered with a variety of surfactants, although significant differences in the degree of mobility control have been reported (Alkan et al. 1991; Bian et al. 2012; Chabert et al. 2012, 2014; Chen et al. 2012; Elhag et al. 2014; Heller 1984, 1994; Khalil and Asghari 2006; Kuehne et al. 1992; McLendon et al. 2012; Prieditis and Paulett 1992; Sanders et al. 2010; Tsau and Heller 1992; Tsau and Grigg 1997; Yang and Reed 1989; Xing et al. 2010; Zeng et al. 2016).

In experiments reported by Chou (1991), foam propagation without oil depends on the initial condition of the core material. Pre-saturating the core with surfactant solution prior to foam generation seemed beneficial for both foam generation and foam propagation. This is also usually recommended task for any foam field application. In Chou's experiments, foam propagation, without oil, was close to the injection rate similar to other reported core flooding experiments (Mannhardt and Svorstøl 1999; Vikingstad and Aarra 2009; Solbakken 2015) using different types of gas.

Vikingstad and Aarra (2009) report foam propagation results in outcrop Berea sandstones at $50{ }^{\circ} \mathrm{C}$ and 120 bar. Two surfactants were tested: a zwitterionic perfluoroalkyl betaine and an anionic $\mathrm{C}_{14-16}$ alpha olefin sulfonate (AOS) surfactant. Two pore volumes of surfactant solution were flooded through the cores prior to foam generation. The foam propagation rate, without oil present in the core, was according to the injection rate $(3.6 \mathrm{~m} / \mathrm{day})$ and generated very strong foams.

The influence of residual oil in the cores showed very different behavior for the two surfactants. The FS-500 surfactant showed significantly delayed propagation rate at residual oil, while the AOS showed faster propagation at Sor and reduced foam strength.

Foam propagation was also studied in a 91-cm reservoir core model (Aarra et al. 1997). Foam was generated by co-injecting methane gas and $1 \mathrm{wt} \%$ AOS surfactant solution into the core at $40 \mathrm{ml} / \mathrm{h}$ at a foam quality of $65 \%$. Two pore volumes of surfactant solution were injected prior to foam generation. The residual oil saturation in the core was $0.1 \mathrm{PV}$. Foam propagation through the core was monitored by 6 pressure ports along the core (Fig. 5). A very stable foam front was propagating at constant front rate through the core. The interstitial velocity in this experiment was $3.9 \mathrm{~m} / \mathrm{D}$, and the low mobility zone moved by approximately $0.035 \mathrm{~m} / \mathrm{D}$. The wettability of the reservoir core material is intermediate- to water-wet based on measurement of the Amott index of 0.48 on similar reservoir core material. The wettability may, in addition to the residual oil saturation, reduce foam propagation rate as foam nucleation sites may be unavailable for foam generation. Mannhardt and Svorstøl (1997) studied foam generation and foam propagation at Snorre reservoir conditions and reported a strong dependence of foam propagation on oil saturation. Higher oil saturation reduced foam propagation and foam propagation in the absence of oil followed the injection rate. Vassenden et al. (1998) reports that the foam front propagates approximately as fast as the injected fluids in a 10-m sandpack without oil. The frontal displacement is in agreement with gas-water frontal movement under steady-state conditions. However, with only an oil saturation of 5 
Fig. 5 Foam propagation using 1 wt $\%$ AOS in reservoir core, foam quality $65 \%, \mathrm{Q}=40 \mathrm{ml} / \mathrm{h}$, at 290 bar and $100{ }^{\circ} \mathrm{C}$

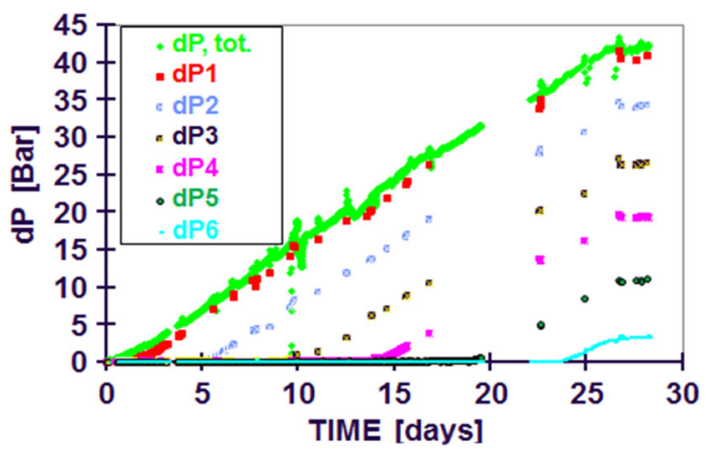

per cent the foam frontal rate was significant lowered. The strong foam propagation front had a velocity of $0,035 \mathrm{~m} / \mathrm{D}$ in the sand pack core model at residual oil saturation of $0,05 \mathrm{PV}$. The delayed foam propagation in the presence of oil can be explained if the foam can mobilize oil by an extraction mechanism. Slow foam propagation was successfully simulated the frontal movement by allowing oil to evaporate into the gas or to solubilize oil in the surfactant solution. The appearance of a high-pressure gradient in a section was interpreted as strong low mobility foam.

\subsection{Influence of Heterogeneity on Foam Propagation}

Effect of lamina and core heterogeneities have been studied in foam experiments in three low permeable Berea sandstone cores. The brine permeability of the core material varied between 67 and $130 \mathrm{mD}$. The core materials were classified as weakly laminated $(67 \mathrm{mD})$ to strongly laminated $(130 \mathrm{mD})$. Foam was generated by co-injecting $0.5 \mathrm{wt} \%$ AOS and $\mathrm{N} 2$ gas at $80 \%$ foam quality, and no oil was present. Foam was generated in all laminated low perm cores and was observed at high pressures (30,120 and 280 bar) and at temperatures of 50 or $100{ }^{\circ} \mathrm{C}$. Foam breakthrough in strongly laminated core material and moderately laminated core material differed from weakly laminated core. Early foam breakthrough was observed where medium- and strong lamination was present $(<0.5 \mathrm{PV})$, whereas the weakly laminated core showed foam breakthrough close to the injection rate.

Heterogeneous reservoirs with large permeability contrasts within the reservoir can give areas of poor sweep during gas injection or water flooding. Foam can be used to divert fluid flow to low permeability areas by blocking or strongly reduce fluid mobility in high permeable areas.

An important evaluation for foam formation in heterogeneous reservoirs seems to be the fact that fluid distribution is controlled by the existing reservoir permeability contrasts and that surfactant is therefore distributed mainly in high permeable areas (Di Julio and Emanuel 1989; Casteel and Djabbarah 1988). Di Jullio and Emmanuel reported two base case parallel corefloods performed by simultaneously water flooding both cores, then injecting water and $\mathrm{CO}_{2}$ alternately (WAG). Average oil recoveries for the two base cases for low permeability core (LPC) were 0 and $0.4 \%$ OOIP for the waterflood and $\mathrm{CO}_{2}$ WAG, respectively, and LPC was almost unswept by water flood and $\mathrm{CO}_{2}$ injection. Foam was able to divert $\mathrm{CO}_{2}$ to the low permeability core. Another paper reports in situ foam generation as an effective method for increasing supercritical $\mathrm{CO}_{2}$ displacement efficiency and found foam to be most effective when $\mathrm{CO}_{2}$ had displaced oil from the more permeable core in their dual core floodings of low- 
and high permeable cores. In fact, during open $\mathrm{CO}_{2}$ injection they observed no oil production from the low permeable core (Casteel and Djabbarah 1988).

From the literature, it is discussed that foam is stronger in high permeable core material. In foam field application, this can be an advantage because these areas are already swept to some lower oil saturation value and this can give increased foam stability.

Foam has also been used for diversion of acid in stimulation jobs (Parlar et al. 1995; Burman and Hall 1986) and reports successful foam diversion of HF acid when treating inorganic damage removal in the Gulf of Mexico.

\section{Foam Stability}

Bulk foam oil interactions have been studied for the $\mathrm{AOS}_{14-16}$ surfactant. It was found that a negative spreading coefficient is not a necessary condition for stable foams. Foam stability was related to transport properties within the foam, larger alkanes were found to stabilize the foam, and this may be connected to solubilization. The hydrocarbon molecular weight seems important for foam stability and decane and shorter alkanes solubilize in the micelles and destabilize the foam (Vikingstad et al. 2005). Calculation of the spreading coefficient for six crude oils showed positive values for the AOS surfactant, but static foam tests showed that the AOS generated stable foams in the presence of some of the crude oils (Vikingstad et al. 2006).

The foam-assisted WAG (FAWAG) has been a large-scale demonstration of foam for mobility control at the Snorre field in the North Sea. The Snorre reservoir pressure is 300 barg, and the temperature is $90{ }^{\circ} \mathrm{C}$. Foam has been applied at the Snorre field both for gas shut off and thereafter as two large-scale mobility processes and the results from the last foam trial on the Western fault block were very conclusive (Svorstøl et al. 1997; Blaker et al. 2002; Skauge et al. 2002; Aarra and Skauge 2002).

The SAG injection method was applied when injecting surfactant solution and gas in Western Fault Block (WFB). A total of 140 tons surfactant was injected into the reservoir separated in two slugs. Interpretations of gas injection periods for the well pair P32-P39 would have suggested gas breakthrough time of less than 29 days, whereas the data after foam injection indicated at least a 5-month period until the injected gas arrived in the production well. Gas/oil ratio was significant lowered compared to pre-foam GOR development which implies that large volumes of gas have been stored in the reservoir.

In interpreting the foam pilot in the Cusiana field, Rossen et al. (2017) discussed foam dry-out as an important factor in foam weakness. Simulations performed for the foam pilot in WFB showed sensitivity to (1) foam strength (2) foam dry-out (3) oil tolerance and (4) adsorption.

Field applications of foam for gas shut off in production wells to reduce gas/oil ratio have shown that the foam stability can last for a long period of time. Different foam generation methods have been applied in pilot successes. The injection method has involved both injection of pre-generated foams and SAG injection to generate foam in situ (Thach et al. 1996; Aarra et al. 1996; Chukwueke et al. 1998).

In some of these cases, a polymer has been added to the surfactant phase to increase the stability of the generated foams. Our experience with polymer-based foams (PEF's) showed that foam gas blocking performance could be increased by adding polymer to the surfactant phase. Experiments were run in a $91 \mathrm{~cm}$ North Sea reservoir core at 290 bar line pressure and at temperatures from 70 or $100{ }^{\circ} \mathrm{C}$. The permeability of the composite reservoir core model was $1.7 \mathrm{D}$. 


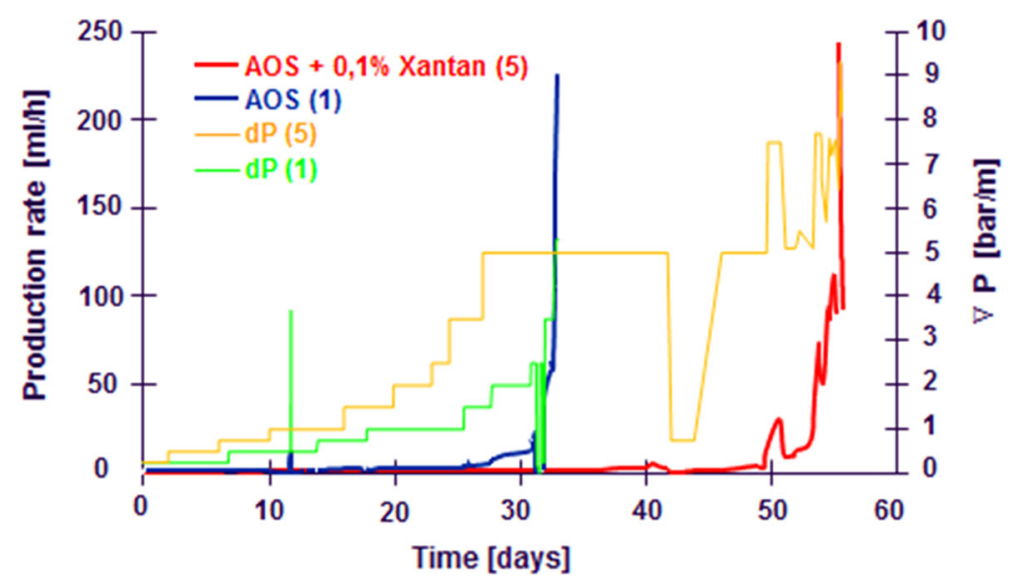

Fig. 6 Gas blocking by foam at different methane pressure gradients

Foam was generated by co-injecting $\mathrm{AOS}_{14-16}$ surfactant solution (or AOS $+0.1 \%$ polymer) and methane gas into the composite core model at $65 \%$ foam quality and total injection rate of $40 \mathrm{ml} / \mathrm{h}$ (Aarra et al. 1997) at residual oil saturation after gas flooding ( $S_{\text {org }} \sim 0.1 \mathrm{PV}$ ). Strong foams were generated, and foams ability to block gas was investigated by applying different methane pressure gradients and monitoring the production rate. Figure 6 shows the gas production rate as a function of the applied pressure gradient, and results show improved stability for the AOS + Xanthan foam compared to AOS alone. The applied pressure gradients applied in these experiments are also higher than typical field pressure gradients.

Even after 40 days of methane injection at high-pressure gradients, the production rate was below $3 \mathrm{ml} / \mathrm{h}$. The pressure gradient was increased to $9 \mathrm{bar} / \mathrm{m}$ and the production rate increased significantly. Reducing the pressure gradient to 0.5 and 0.75 gave low production rates thus showing that the foam was not broken, or that some foam had been regenerated.

In a previous paper, we investigated the ability of foam to reduce seawater permeability and the longevity of reduced seawater permeability (Aarra et al. 2014). The foam core flooding experiments were performed without oil to better compare $\mathrm{CO}_{2}$-foam properties to $\mathrm{N}_{2}$-foams, and the influence of mass transfer on foam stability for $\mathrm{CO}_{2}$ foams was studied.

In this study, seawater blocking experiments were performed after ending the foam generation sequence. Seawater was injected at $8 \mathrm{ml} / \mathrm{h}$ (equal to the surfactant solution rate during foam generation), and the seawater permeability was measured at different times and involved injection of several pore volumes of seawater.

For $\mathrm{N}_{2}$ foams, the effect on seawater relative permeability development with pore volumes water injected was studied both at 30 bar and at 280 bar and showed an apparent seawater permeability $(\mathrm{k}(\mathrm{ssw}) / \mathrm{k}(100 \%$ seawater $)$ ) was below 0.1 . The effect was long lasting and significantly stronger in the presence of foam compared to no surfactant cases.

The use of equilibrated fluids made a great impact on the ability of $\mathrm{CO}_{2}$-foams to reduce seawater permeability. When using non-equilibrated fluids, high water permeability with foam present in the core was measured. Probably, mass transfer between fluid phases and especially $\mathrm{CO}_{2}$ dissolving in the injected brine was spontaneous according to Gibbs free energy and led to reduced foam stability and increased water saturation as using equilibrated fluids changed the situation completely even at 30 bar. In these experiments, $\mathrm{CO}_{2}$ was saturated with brine and the $0.5 \mathrm{wt} \%$ AOS surfactant solution and also the synthetic seawater were 
saturated with $\mathrm{CO}_{2}$. The presence of equilibrated $\mathrm{CO}_{2}$-foams in the core gave a strong and long-lasting reduction in seawater permeability as shown in two independent experiments.

This long-lasting reduction in seawater permeability after foam can, in our opinion, not be explained as an ordinary two-phase effect. Without foam present in the core, the seawater permeability increases until trapped gas saturation $\left(S_{\mathrm{gt}}\right)$ has developed. The reduction in $k_{\mathrm{rw}}$ depends on the magnitude of $S_{\mathrm{gt}}$ and the seawater relative permeability curve, but we believe that the large decrease in water permeability exceeds expected changes in $S_{\mathrm{gt}}$ (Skauge 1996; Skauge and Larsen 1994). There are some observations in the literature of water fingering through the foam (Nguyen et al. 2009) and we cannot exclude that this phenomena also can be present in our experiments.

\section{Conclusions}

Foam is generated at low surfactant concentration even below the CMC (critical micelle concentration).

In situ generation of foam is complex and difficult in oil wet carbonate rocks, where continuous oil films may occur. Foam generation is dependent on available water wet nucleation sites to form foam bubbles.

Foam propagation in porous medium has been summarized, and propagation rate for a given experiment seems to be constant. Laboratory studies confirm a foam propagation rate of 1-4 cm/day. Lower MRF may accelerate the foam propagation.

Past and present field trials on foam lack information about the rate of foam propagation, and future field pilots are encourage including observation wells in order to gain information of field-scale foam propagation.

Stability of foam has been studied in laboratory and field tests, and data confirm long-term stability of foam. The potential economic benefit of using foam in relation to various process optimizations for EOR can be substantial as the operational cost is low. The foam processes, both production- and injection well treatments, are considered rather low-cost processes. We encourage the oil industry to use foam further to improve the economics of their mature oil fields.

Acknowledgements Arne Skauge acknowledges Energi Simulations, Calgary, Alberta, Canada, for financial support.

Open Access This article is distributed under the terms of the Creative Commons Attribution 4.0 International License (http://creativecommons.org/licenses/by/4.0/), which permits unrestricted use, distribution, and reproduction in any medium, provided you give appropriate credit to the original author(s) and the source, provide a link to the Creative Commons license, and indicate if changes were made.

\section{References}

Aarra, M.A., Skauge A.: Status of foam application in the North Sea. Presented at the international energy agency symposium, Edinburgh, August (2000)

Aarra, M., Søgnesand, S., Stenhaug, M., Skauge, A.: A foam pilot test aimed at reducing gas inflow in a production well at the oseberg field. Pet. Geosci. 2, 125-132 (1996)

Aarra, M.G., Ormehaug, P.A., Skauge, A.: Foams for GOR control-improved stability by polymer additives. In: Paper 10 in Proceedings of the 9th European Symposium on Improved Oil Recovery, The Hague, The Netherlands, 20-22 October (1997) 
Aarra, M.G., Skauge, A., Martinsen H.A.: FAWAG a breakthrough for EOR in the North Sea. SPE 77695 prepared for the SPE Annual Technical Conference and Exhibition, San Antonio, 29 September-2 October (2002)

Aarra, M.G., Ormehaug, P.A., Skauge, A., Mesalmeh, S.: Experimental study of $\mathrm{CO}_{2}$ - and methane-foam using carbonate core material at reservoir conditions. SPE 141614, Paper Prepared for presentation at the SPE Middle East Oil and Gas Show and Conference held in Manama, Bahrain, 20-23 March (2011)

Aarra, M.G., Skauge, A., Solbakken, J., Ormehaug, P.A.: Properties of $\mathrm{N}_{2}$ - and $\mathrm{CO}_{2}$-foams as a function of pressure. J. Pet. Sci. Eng. 116, 72-80 (2014)

Alkan, H., Goktekin, A., Satman, A.: A laboratory study of $\mathrm{CO}_{2}$-foam process for Bati Raman field, Turkey. Presented at the SPE Middle East Oil Show, Bahrain, Paper SPE 21409, 16-19 November (1991)

Almajid, M.M., Kovscek, A.R.: Adv. Colloid Interface Sci. 233, 65-82 (2016)

Apaydin, O.G., Kovscek, A.R.: Surfactant concentration and end effects on foam flow in porous media. Transp. Porous Media 43, 511-536 (2001)

Bian, Y., Penny, G., Sheppard, N.C.: Surfactant formulation evaluation for carbon dioxide foam flooding in heterogeneous sandstone reservoirs. Presented at the SPE Improved Oil Recovery Symposium, Tulsa, Oklahoma, Paper SPE 154018. 14-18 April (2012)

Blaker, T., Aarra, M.G., Skauge, A., Rasmussen, L., Celius, H.K., Martinsen, H.A., Vassenden, F.: Foam for Gas Mobility Control in the Snorre Field: The FAWAG Project. SPERE\&E, pp. 317-323, September (2002)

Burman, J.W., Hall, B.E.: Foam as a diverting technique for matrix sandstone stimulation. Society of Petroleum Engineers (1986). https://doi.org/10.2118/15575-MS

Casteel, J.F., Djabbarah, N.F.: Sweep improvements in $\mathrm{CO}_{2}$ flooding by use of foaming agents. SPERE 3(4), 1186-1192 (1988)

Chabert, M., Morvan, M., and Nabzar, L.: Advanced screening technologies for the selection of dense $\mathrm{CO}_{2}$ foaming surfactants. Presented at the 18th SPE Improved Oil Recovery Symposium, Paper SPE 154147, Tulsa, Oklahoma, 14-18 April (2012)

Chabert, M., Nabzar, L., Beunat, V., Lacombe, E., Cuenca, A.: Impact of surfactant structure and oil saturation on the behaviour of dense $\mathrm{CO}_{2}$ foams in porous media. Presented at the SPE Improved Oil Recovery Symposium, Paper SPE 169116. Tulsa, Oklahoma, 12-16 April (2014)

Chen, Y., Elhag, A.S., Poon, B.M., Cui, L., Ma, K., Liao, S.Y., Omar, A., Worthen, A.J., Hirasaki, G.J., Nguyen, Q., Johnston, K.P.: Ethoxylated cationic surfactants for $\mathrm{CO}_{2}$ EOR in high temperature, high salinity reservoirs. Presented at the SPE Improved Oil Recovery Symposium, Paper SPE 154222. Tulsa, Oklahoma, 14-18 April (2012)

Chou, S.I.: Conditions for generating foams in porous media. Presented at the 66th Annual Technical Conference and Exhibition of SPE, Paper SPE 22628. Dallas, Texas, 6-9 October (1991)

Chukwueke, V.O., Bouts, M.N., van Dijkum, C.E.: Gas shut-off foam treatments. Society of Petroleum Engineers (1998)

de Vries, A.S., Wit, K.: Rheology of gas/water foam in the quality range relevant to steam foam. SPERE, pp. 185-192 (1990)

Del Grosso V.A., Mader, C.V.: Speed of sound in pure water. J. Acoust. Soc. Am. 52, 1442 (1972). https://doi. org/10.1121/1.1913258

Di Julio, S.S., Emanuel, A.S.: Laboratory study of foaming surfactant for $\mathrm{CO}_{2}$ mobility control. SPE J. 4, 136-142 (1989)

Dixit, A., Tsau, J.S., Heller, J.P.: Laboratory study on surfactant-based selective mobility control. Presented at the 1994 SPE Permian Basin Oil \& Gas Recovery Conference, Midland, Texas, Paper SPE 27729. 16-18 March (1994)

Du, D.X., Beni, A.N., Farajzadeh, R., Zitha, P.L.J.: Effect of water solubility on carbon dioxide foam flow in porous media: an X-ray computed tomography study. Ind. Eng. Chem. Res. 47, 6298-6306 (2008)

Elhag, A.S., Chen, Y., Chen, H., Reddy, P.P., Cui, L., Worthen, A.J., Ma, M., Hirasaki, G.J., Nguyen, Q.P., Biswal, S.L., Johnston, K.P.: Switchable amine surfactants for stable $\mathrm{CO}_{2}$ /brine foams in high temperature, high saline reservoirs. Paper SPE 169041 presented at the SPE Improved Oil Recovery Symposium, Tulsa, Oklahoma, 12-16 April (2014)

Enick, R.M., Olsen, D.K.: Mobility and conformance control for carbon dioxide enhanced oil recovery $\left(\mathrm{CO}_{2}\right.$-EOR) via thickeners, foams, and gels-a detailed literature review of 40 years of research. DOE/NETL-2012/1540; Activity 4003.200.01, Report prepared for the U.S. Department of Energy (2012)

Ettinger, R.E., Radke, C.J.: Influence on foam texture on steady foam flow in Berea sandstone. SPERE 7, 83-90 (1992)

Farajzadeh, R., Andrianov, A., Bruining, H., Zitha, P.L.J.: Comparative study of $\mathrm{CO}_{2}$ and $\mathrm{N}_{2}$ foams in porous media at low and high pressure-temperatures. Ind. Eng. Chem. 48, 4542-4552 (2009) 
Fekarcha, L., Tazerouti, A.: Surface activities, foam properties, HLB, and Krafft point of some nalkanesulfonates (C14-C18) with different isometric distributions. J. Surfactant Deterg. 15, 419-431 (2012)

Friedmann, F., Chen, W.H., Gauglitz, P.A.: Experimental and simulation study of high-temperature foam displacement in porous media. SPERE, February 37-45 (1991)

Gauglitz, P.A., Friedmann, F., Kam, S.I., Rossen, W.R.: Foam generation in homogeneous porous media. Chem. Eng. Sci. 57(19), 4037-4052 (2002)

Heller, J.P.: Reservoir application of mobility control foams in $\mathrm{CO}_{2}$ floods. Paper SPE/DOE 12644 presented at the SPE/DOE Fourth Symposium on Enhanced Oil Recovery, Tulsa, Oklahoma, 15-18 April (1984)

Heller, J.P.: $\mathrm{CO}_{2}$ foams in enhanced oil recovery. In: Schramm, L.L. (ed.) Foams: Fundamentals and Application in the Petroleum Industry, pp. 201-234. American Chemical Society, Washington (1994)

Heuer, G.J., Jacobs, C.L.: Control of GOR in producing wells. U.S. Patent No. 3368624 (1968)

Hirasaki, G.J.: The steam-foam process. J. Pet. Technol. 41, 449-456 (1989)

Hirasaki, G.J., Miller, C.A., Szafranski, R., Lawson, L.B., Tanzil, D., Jackson, R.E., Londergan, J., Meinardus, H.: Field demonstration of the surfactant/foam process for aquifer remediation. Paper SPE 39292 Presented at the 1997 SPE Annual Technical Conference and Exhibition in San Antonio, Texas, 5-8 October (1997)

Høgseth, E., Hedwig, G., Høiland, H.: Rubidium clock sound velocity meter. Rev. Sci. Instr. 71(12), 4679-4680 (2000)

Holm, L.W., Garrison, W.H.: $\mathrm{CO}_{2}$ diversion with foam in an immiscible $\mathrm{CO}_{2}$-field project. SPERE, February, pp. 112-118 (1988)

Holt, T., Vassenden, F., Svorstøl, I.: Effect of pressure on foam stability; implications for foam screening. Paper SPE 35398, Presented at the 1996 SPE/DOE 10th Symposium on Improved Oil Recovery, Tulsa, Oklahoma, 21-24 April (1996)

Khalil, F., Asghari, K.: Application of $\mathrm{CO}_{2}$-foam as a means of reducing carbon dioxide mobility. JCPT 45(5), 37-42 (2006)

Kibodeaux, K.R.: Experimental and theoretical studies of foam mechanisms in enhanced oil recovery and matrix acidization applications. PhD dissertation, The University of Texas at Austin (1997)

Kovscek, A.R., Radke, C.J.: Fundamentals of foam transport in porous media. In: Schramm, L.L. (ed.) Foams: Fundamentals and Application in the Petroleum Industry, pp. 115-163. American Chemical Society, Washington (1994)

Krause, R.E., Lane, R.H., Kuehne, D.L., Bain, G.F.: Foam treatment of producing wells to increase oil production at prudhoe bay. Paper SPE/DOE 21191, Presented at the SPE/DOE Eighth Symposium on Enhanced Oil Recovery, Tulsa, Oklahoma, 22-24 April (1992)

Kuehne, D.L., Frazier, R.H., Cantor, J., Horn, W.: Evaluation of surfactants for $\mathrm{CO}_{2}$ mobility control in dolomite reservoirs. Paper SPE/DOE 24177 Presented at the SPE/DOE Eighth Symposium on Enhanced Oil Recovery, Tulsa, Oklahoma, 22-24. April (1992)

Kuhlman, M.I., Falls, A.H., Hara, S.K., Monger-McClure, T.G., Borchardt, J.K.: $\mathrm{CO}_{2}$ foam with surfactants used below their critical micelle concentrations. SPERE 7(4), 445-452 (1992)

Liontas, R., Ma, K., Hirasaki, G.J., Biswal, S.L.: Neighbor-induced bubble pinch-off: novel mechanisms of in situ foam generation in microfluidic channels. Soft Matter 9, 10971-10984 (2013)

Mannhardt, K., Svorstøl, I.: Foam propagation in Snorre reservoir core-effects of oil saturation and ageing. Paper 52 in Proceedings of the 9th European Symposium on Improved Oil Recovery, The Hague, The Netherlands, 20-22 October (1997)

Mannhardt, K., Svorstøl, I.: Effect of oil saturation on propagation in Snorre reservoir core. JPSE 23(3-4), 189-200 (1999)

Mannhardt, K., Svorstøl, I.: Surfactant concentration for foam formation and propagation in Snorre reservoir core. JPSE 30(2), 105-119 (2001)

Mannhardt, K., Novosad, J.J., Schramm, L.L.: Comparative evaluation of foam stability to oil. SPE Reserv. Eval. Eng. 3(1), 23-34 (2000)

Manrique, E., Thomas, C., Ravikiran, R., Izadi, M., Lantz, M., Romero, J., Alvardo, V.: EOR: current status and opportunities. Paper SPE 130113, Presented at the SPE Improved Oil Recovery Symposium, Tulsa, Oklahoma, 24-28 April (2010)

McLendon, W.J., Koronaios, P., McNulty, S., Enick, R.M., Biesmans, G., Miller, A., Salazar, L., Soong, Y., Romanov, V., Crandall, D.: Assessment of $\mathrm{CO}_{2}$-soluble surfactants for mobility reduction using mobility measurements and CT imaging. Paper SPE 154205, Presented at the SPE Improved Oil Recovery Symposium, Tulsa, Oklahoma, 14-18 April (2012)

Nguyen, Q.P., Zitha, P.L.J., Currie, P.K., Rossen, W.R.: CT Study of liquid diversion with foam, SPE Production \& Operations, 24(1), 12-21 (2009). 
Ocampo, A., Restrepo, A., Cifuentes, H., Hester, J., Orozco, N., Gil, C., Castro, E., Lopera, S., Gonzalez, C.: Successful foam EOR pilot in a mature volatile oil reservoir under miscible gas injection. Paper IPTC 16984, Presented at the International Petroleum Technology Conference, Beijing, China, 26-28 March (2013)

Ocampo, A., Restrepo, A., Lopera, S.H., Mejia, J.M.: Creation of in situ EOR foams by the injection of surfactant in gas dispersions-lab confirmation and field application, SPE 190219-MS. Society of Petroleum Engineers (2018). https://doi.org/10.2118/190219-MS

Ocampo-Florez, A., Restrepo, A., Rendon, N., Coronado, J., Correa, J.A., Ramirez, D.A. Lopera, S.H.: Foams prove effectiveness for gas injection conformance and sweep efficiency improvement in a low porosity fractured reservoir-field pilots. International Petroleum Technology Conference (2014)

Osterloh, W.T., Jante Jr., M.J.: Effects of gas and liquid velocity on steady-state foam flow at high temperatures. Paper SPE/DOE 24179, Presented at the SPE/DOE Eighth Symposium on Enhanced Oil Recovery, Tulsa, OK, April 22-24 (1992)

Parlar, M., Parris, M.D., Jasinski, R.J., Robert, J.A.: An experimental study of foam flow through Berea sandstone with applications to foam diversion in matrix acidizing. Paper SPE 29678, Presented at the Western Regional Meeting, Bakersfield, California, 8-10 March (1995)

Persoff, P., Radke, C.J., Preuss, K., Benson, S.M., Witherspoon, P.A.: A laboratory investigation of foam flow in sandstone at elevated pressure. SPERE, August, pp. 365-372 (1991)

Prieditis, J., Paulett, G.S.: $\mathrm{CO}_{2}$-foam mobility tests at reservoir conditions in san Andreas cores. Paper SPE/DOE 24178, Presented at the SPE/DOE Eighth Symposium on Enhanced Oil Recovery, Tulsa, Oklahoma, 22-24 April (1992)

Rohani, M.R., Ghotbi, C., Badakhshan, A.: Foam Stability and Foam-oil Interactions. Pet. Sci. Technol. 32, $1843-1850$ (2014)

Rossen, W.R.: Foams in enhanced oil recovery in foams: theory, measurements, and applications. In: Prud'homme, R.K., Khan, S.A. (eds.) Surface Science Series, vol. 57. Marcel Dekker, New York, pp. 413-464 (1996)

Rossen, W.R., Ocampo, A., Restrepo, A., Cifuentes, H.D., Marin, J.: Long-time diversion in surfactant alternating-gas foam enhanced oil recovery from a field test, SPE 170809-PA. SPE Reservoir Evaluation and Engineering, pp. 1-7 (2017)

Sanchez, J.M., Schechter, R.S.: Surfactant effects on the two-phase flow of steam-water and nitrogen-water through permeable media. JPSE 3, 185-199 (1989)

Sanders, A.W., Nguyen, Q.P., Nguyen, N.M., Adkins, S.S., Johnston, K.P.: Twin-tailed surfactants for creating $\mathrm{CO}_{2}$-in-water macroemulsions for sweep enhancement in $\mathrm{CO}_{2}$-EOR. Paper SPE 137689, Presented at the Abu Dhabi International Petroleum Exhibition \& Conference, Abu Dhabi, United Arabic Emirates, 1-4 November (2010)

Seright, R.S.: Improved techniques for fluid diversion in oil recovery processes. Final report, DOE/BC/1488015, Contract No. DE-AC22-92BC14880, U.S. DOE, January (1996)

Siddiqui, S., Talabani, S., Saleh, S.T., Islam, M.R.: A laboratory investigation of foam flow in low-permeability Berea sandstone cores. Paper SPE 37416, Presented at the 1997 SPE Production Operations Symposium, Oklahoma City, March 9-12 (1997)

Simjoo, M., Dong, Y., Andrianov, A., Talanana, M., Zitha, P.L.J.: Novel insight into foam mobility control. SPE J. 18, 416-427 (2013)

Skauge, A., Aarra, M.G., Surguchev, L., Martinsen, H.A.: Foam assisted WAG, a summary of field experience at the Snorre field. Paper SPE 75157, Presented at the SPE/DOE Improved Oil Recovery Symposium, Tulsa, OK, April (2002)

Skauge, A., Larsen, J.A.: Three-phase relative permeabilities and trapped gas measurements related to WAG processes. Paper SCA 9421, Presented at the 1994 International Symposium of the Society of Core Analysists, Stavanger, September 12-14 (1994)

Skauge, A.: Influence of wettability on trapped non-wetting phase saturation in three-phase flow. In: Proceedings Fourth International Symposium on Wettability and it's Effect on Oil Recovery, Montpellier, France, September (1996)

Skoreyko, F.A., Villavicencio, A.P., Rodriguez Prada, H., Nguyen, Q.P.: Development of a new foam EOR model from laboratory and field data of the naturally fractured Cantarell field. Society of Petroleum Engineers (2011). https://doi.org/10.2118/145718-MS.

Smith, D.H., Jikich, S.A.: Foams and surfactants for improved underground storage of natural gas by blockage of water coning. Paper SPE-26908-MS, Presented at the SPE Eastern Regional Meeting, Pittsburgh, Pennsylvania, USA, 2-4 November (1993)

Solbakken, J.S.: Experimental studies of $\mathrm{N}_{2}$ - and $\mathrm{CO}_{2}$-foam properties in relation to enhanced oil recovery applications. PhD thesis, University of Bergen (2015) 
Solbakken, J.S., Skauge, A., Aarra, M.G.: Foam behaviour in low permeability and laminated sandstones. Energy Fuels 28(2), 803-815 (2014)

Svorstøl, I., Blaker, T., Tham, M.J., Hjellen, A.: A production well foam pilot in the north sea Snorre field-application of foam to control premature gas breakthrough. Presented at the 9th European Symposium on Improved Oil Recovery, The Hague, The Netherlands, 20-22 October (1997)

Thach, S., Miller, K.C., Lai, Q.J., Sanders, G.S., Styler, J.W., Lane, R.H.: Matrix gas shut-off in hydraulically fractured wells using polymer-foams. Society of Petroleum Engineers, SPE 36616-MS (1996). https:// doi.org/10.2118/36616-MS

Thompson, K.E., Gdanski, R.D.: Laboratory study provides guidelines for diverting acid with foam. SPE Prod. Facil. 8(4), 285-290 (1993)

Tsau, J.S., Grigg, R.B.: Assessment of foam properties and effectiveness in mobility reduction for $\mathrm{CO}_{2}$-foam floods. Paper SPE 37221, Presented at the SPE International Symposium on Oilfield Chemistry, Houston, Texas, 18-21 February (1997)

Tsau, J.S., Heller, J.P.: Evaluation of surfactants for $\mathrm{CO}_{2}$-foam mobility control. Paper SPE 24013, Presented at the 1992 SPE Permian Basin Oil and Gas Conference, Midland, Texas, 18-20 March (1992)

Turta, A.T., Singhal, A.K.: Field foam applications in enhanced oil recovery projects: screening and design aspects. Paper SPE 48895, presented at the SPE International Oil and Gas Conference and Exhibition, Beijing, China, 2-6 November (1998)

Vassenden, F. Holt, T., Solheim, A.: Foam propagation on semi-reservoir scale. Paper SPE 39682 (1998)

Vikingstad, A.K., Aarra, M.G.: Comparing the static and dynamic foam properties of a fluorinated and an alpha olefin sulfonate surfactant. JPSE 65, 105-111 (2009)

Vikingstad, A.K., Skauge, A., Høiland, H., Aarra, M.: Foam-oil interactions analysed by static foam tests. Colloid Surf. A Physicochem. Eng. Asp. 260(1-3), 189-198 (2005)

Vikingstad, A.K., Aarra, M.G., Skauge, A.: Effect of surfactant structure on foam-oil interactions comparing fluorinated surfactant and alpha olefin sulfonate in static foam tests. Colloids Surf. A Phys. Chem. Eng. Asp. 279, 105-112 (2006)

Xing, D., Wei, B., McLendon, W., Enick, R., McNulty, S., Trickett, K., Mohamed, A., Cummings, S., Eastoe, J., Rogers, S., Crandall, D., Tennant, B., McLendon, T., Romanov, V., Soong, Y.: $\mathrm{CO}_{2}$-soluble, nonionic, water-soluble surfactants that stabilize $\mathrm{CO}_{2}$-in-brine foams. Paper SPE 129907, Presented at the SPE Improved Oil Recovery Symposium, Tulsa, Oklahoma, 24-28 April (2010)

Yang, S.H., Reed, R.L.: Mobility control using $\mathrm{CO}_{2}$-foams. Paper SPE 19689, Presented at the $64^{\text {th }}$ Annual Technical Conference and Exhibition of SPE, San Antonio, Texas, 8-11 October (1989)

Yu, G., Rossen, W. R., Vincent-Bonnieu, S.: Foam generation with flow rate: effect of surfactant concentration and gas fraction. SPE 190398-MS, Society of Petroleum Engineers (2018)

Zeilinger, S.C., Wang, M., Kibodeaux, K.R., Rossen, W.R.: Improved prediction of foam diversion in matrix acidization. Paper SPE 29529, Presented at the Production Operations Symposium, Oklahoma City, 2-4 April (1995)

Zeng, Y., Farajzadeh, R., Eftekhari, A.A., Vincent-Bonnieu, S., Muthuswamy, A., Rossen, W.R., Hirasaki, G.J., Biswal, S.L.: Role of gas type on foam transport in porous media. Langmuir 32(25), 6239-6245 (2016)

Zhdanov, S.A., Amiyan, A.V., Surguchev, L.M., Castanier, L.M., Hanssen J.E.: Application of foam for gas and water shut-off: review of field experience. Paper SPE 36914, Presented at the SPE European Petroleum Conference, Milan, Italy, 22-24 October (1996)

Zhou, Z., Rossen, W.R.: Applying fractional flow theory to foam processes at the limiting capillary pressure. SPE 24180, Tulsa, OK, 249 (1992)

Publisher's Note Springer Nature remains neutral with regard to jurisdictional claims in published maps and institutional affiliations. 